\title{
Put Out Your Tongue! The Role of Clinical Insight in the Study of the History of Medicine
}

\author{
MARTIN EDWARDS*
}

\begin{abstract}
Keywords: Tongue Inspection; Tongue Diagnosis; NineteenthCentury Clinical Examination; Nineteenth-Century Diagnostics; Clinical Experience
\end{abstract}

Historians of medicine are often gloomily familiar with clinicians' incursions into their intellectual arena. We physicians offer hagiographic biographies of obscure nineteenthcentury medical figures, triumphalist narratives of medical progress and - the most heinous offence - retrospective diagnosis of ailments afflicting historical characters. But clinicians have also offered some excellent insights to the discipline. As a medical practitioner, I intend to argue that clinical insight can be valuable; not in providing answers here, clinicians' contemporary interpretations of disease and its treatment can lead us to become unstuck - but in raising questions which might not occur to historians.

Examples of my own clinical experience prompting historical research questions include the fiendish difficulty, for a practitioner, of judging whether a remedy really is effective for a particular patient; ${ }^{1}$ and the curious historical rise and fall of bed rest as a therapeutic agent. In this paper, I describe a further example; the extensive nineteenth-century use of tongue inspection as a diagnostic tool. The ubiquity of tongue inspection during this period frequently appears to strike historians as unremarkable, for they assume that examination of the tongue intrinsically conveys considerable diagnostic information. Not so! From a modern clinical perspective, the diagnostic value of tongue inspection is highly limited, and generally localised to intra-oral pathology; whereupon its widespread nineteenth-century adoption immediately generates some profound and fascinating questions.

\section{The Ubiquity of Tongue Inspection in the Nineteenth Century}

New medical students at King's College Hospital were warned by Sir Thomas Watson in his introductory lecture in 1871: 'A patient would think you careless, or ignorant of your craft, if you did not, at every visit, look at his tongue, as well as feel his pulse. ${ }^{2}$ Tongue inspection was an invariable component of proper examination, and appeared to be afforded privileged diagnostic status: 'No organ more quickly indicates derangement,

(C) Martin Edwards, 2011.

* Martin Edwards, Honorary Research Associate, The Wellcome Trust Centre for the History of Medicine at UCL, and General Practitioner, The Jenner Practice, 201 Stanstead Road, London SE23 1HU, UK. Email: martin.edwards@ucl.ac.uk

\footnotetext{
${ }^{1}$ For the outcome of this line of enquiry see Martin Edwards, Control and the Therapeutic Trial: Rhetoric and Experimentation in Britain, 1918-48 (Amsterdam: Rodopi, 2007).

${ }^{2}$ Thomas Watson, Lectures on the Principles and Practice of Physic (London: Longmans, Green \& Co., 1871), 145-6.
} 


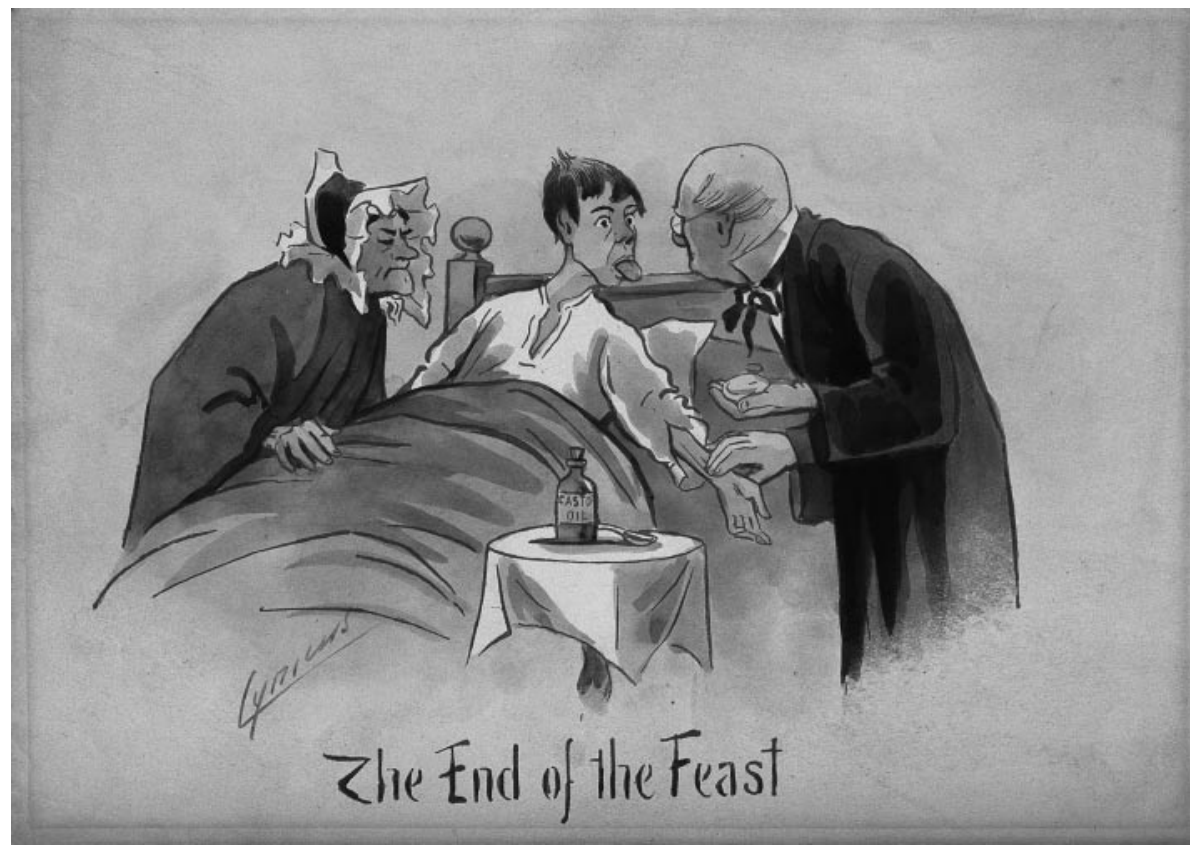

Figure 1: A patient poking out his tongue and having his pulse taken by a physician. Watercolour by M. Henderson. Courtesy: Wellcome Library, London.

however slight; in every case it sympathises.... ${ }^{3}$ Dr Fairlie Clarke considered that 'In the ordinary practice of our profession we constantly desire the patient to "put out his tongue", and there is much which we can learn with respect to the condition of his general health from a simple glance. ${ }^{4}$ Thomas Newham wrote: 'Every practitioner is in the habit of looking at the tongue in all cases of internal, and in most cases of external, disease', 5 and agreed that a simple glance was sufficient to provide valuable information. A joke illustrates Victorian patients' expectations that their doctor would examine their tongue: 'Patient. Doctor, I can't sleep at night. I tumble and toss until morning. Doctor. H'm, that's bad. Let me see your tongue. (After diagnosis.) Physically, you are all right. Perhaps you worry over that bill you've owed me for the past two years. ${ }^{6}$

Contemporary iconography frequently depicts the doctor at work inspecting tongues, whether in his surgery, at the patient's home, or even in the pub. ${ }^{7}$ My analysis of case reports, and of in-patient clerking notes from St Bartholomew's Hospital in London, supports the contention that throughout the nineteenth and early twentieth

\footnotetext{
${ }^{3}$ Andrew Whyte Barclay, A Manual of Medical Diagnosis: An Analysis of the Symptoms and Signs of Disease (London: John Churchill, 1857), 33.

${ }^{4}$ W.F. Clarke, A Treatise on the Diseases of the Tongue (London: Renshaw, 1873), 34.
}

\footnotetext{
${ }^{5} \mathrm{~T}$. Newham, 'On the Tongue as a Means of Diagnosis', The Lancet, 63, 1608 (1854), 661-2.

${ }^{6}$ Anon., 'Pilferings', Pick-Me-Up Magazine, 4, 27 October 1888 .

${ }^{7} \mathrm{~A}$ few examples to illustrate this point are included within this text.
} 


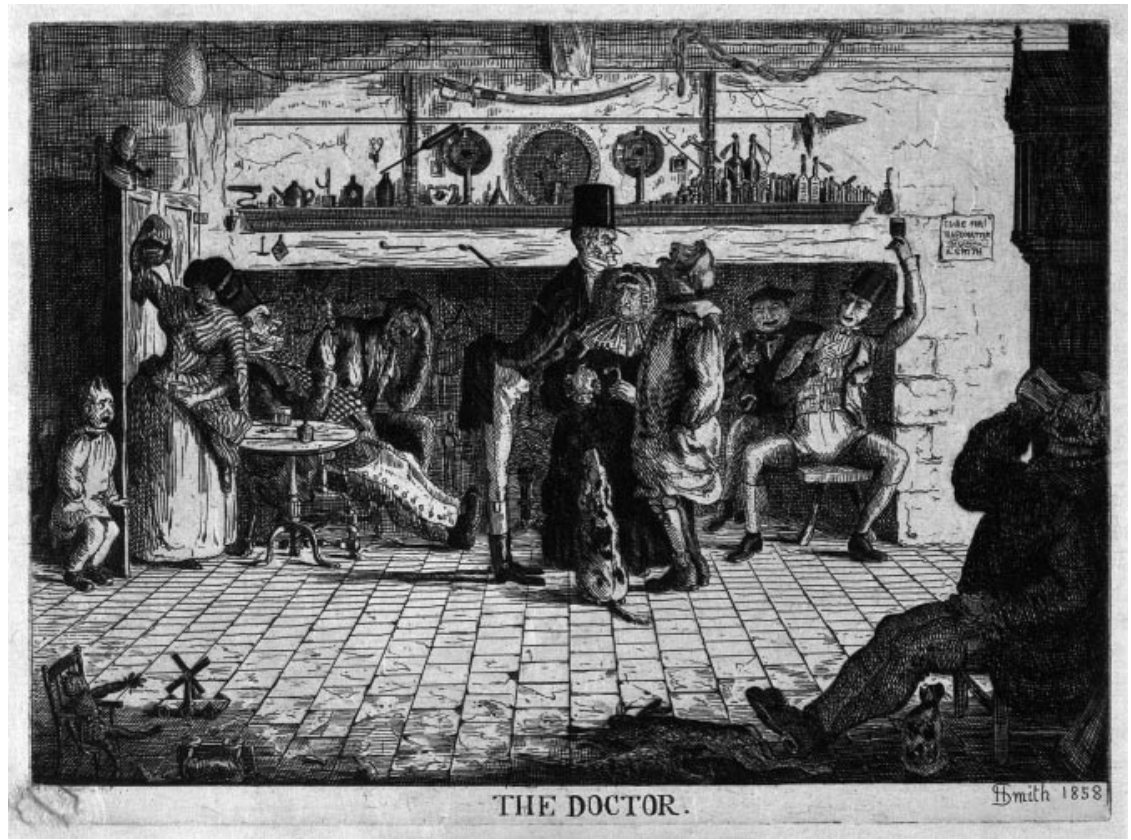

Figure 2: A doctor examining a man's tongue in a country tavern. Etching by H. Smith, 1858. Courtesy: Wellcome Library, London.

century, doctors did routinely inspect the tongue, and record - albeit briefly - their findings. ${ }^{8}$

\section{The Origins of Nineteenth-Century Tongue Inspection}

This widespread adoption of tongue examination appears to be peculiar to the nineteenth and early twentieth centuries, and extended to the USA and Europe, though my analysis concerns Britain alone. John Haller, in a brief paper, ${ }^{9}$ suggests an eighteenth-century origin, although the clinicians he credits with its dissemination - John Abernethy (1764-1831) and François Broussais (1772-1838) - were, in terms of their working lives, largely early nineteenth-century figures. Tongue inspection received little mention in diagnostic treatises prior to the late eighteenth century, except in specific conditions such as fever, and pre-nineteenth-century case reports only occasionally included a description of the tongue. Nevertheless, nineteenth-century clinicians appeared keen to emphasise the ancient origins of the practice; to Fairlie Clarke, the tongue 'is an organ which has been examined from the earliest times as affording an index to the state of the general health, 10 and Howslip Dickinson, an enthusiast for the diagnostic potential of tongue inspection,

\footnotetext{
${ }^{8}$ This statement is based upon my ongoing analysis of published eighteenth and nineteenthcentury case reports, and examination of archived case notes from St Bartholomew's Hospital.
}

\footnotetext{
${ }^{9}$ J.S. Haller Jr., 'The Foul Tongue: A 19th Century Index of Disease', Western Journal of Medicine, 137 (1982), 258-64.

${ }^{10}$ Clarke, op. cit. (note 4), preface.
} 


\section{Martin Edwards}

traced its lineage through Hippocrates, Aretaeus, Paulus Aegineta and Avicenna. ${ }^{11}$ Even Dickinson, however, was forced to concede that references to the tongue throughout history were 'fewer and slighter than would be expected', ${ }^{12}$ and that Hippocrates mentioned the tongue infrequently, and in relation almost entirely to fevers.

Nancy Holroyde-Downing has examined the centuries-old tradition of tongue diagnosis in Chinese traditional medicine, and suggests that Western physicians were inspired to adopt tongue inspection by translations of Oriental texts as early as the seventeenth century. ${ }^{13}$ Whatever its origins, however, it appears that tongue examination did not become widespread until the nineteenth century, and its proponents certainly did not refer to Oriental antecedents when they constructed their appeals to Antiquity. As Haller has suggested, John Abernethy might have been an influential figure in its adoption: a pupil and disciple of John Hunter, and surgeon at St Bartholomew's Hospital in London, Abernethy promoted the notion of 'sympathy', whereby disease in one location could produce physical changes in distant organs. Sympathy, he felt, was probably mediated through nerves, and was particularly apparent between the tongue and alimentary organs: 'The state of the tongue is, in general, an infallible criterion of a disordered condition of the stomach.... ${ }^{14}$ Reputedly brusque and impolite to his patients, ${ }^{15}$ he popularised and promoted his views through his book, ${ }^{16}$ which he frequently exhorted his patients to buy, thereby earning the soubriquet 'Doctor My-Book'.

Tongue inspection continued to feature in medical practice, textbooks and case reports throughout the early twentieth century, though with gradually diminishing popularity, and serious challenges appeared towards the middle decades. By 1944, The Lancet could speculate "whether there was much substance behind the wise look of the old-time physician as he felt the patient's pulse and looked at his tongue, ${ }^{17}$ and by the 1960 s, studies by clinicians such as Trevor Howell, who examined the tongues of fifty demented women and found no correlation between the appearance of their tongues and the presence of constipation, ${ }^{18}$ helped give the lie to earlier claims for the diverse value of the tongue in diagnosis.

\section{Why Did Nineteenth-Century Physicians Inspect the Tongue?}

This inquiry was sparked by an apparent mismatch between the ubiquity of tongue inspection in the nineteenth century, and its relatively poor yield as a diagnostic tool according to current medical thinking. Indeed, such a mismatch appeared to exist even in the nineteenth century. Sweeping claims for the immense and privileged diagnostic value of tongue inspection appear at odds with the relatively paucity of accounts of the tongue in actual disease descriptions in medical textbooks, which generally confined its changes to an

\footnotetext{
${ }^{11}$ W. Howslip Dickinson, The Tongue as an Indication in Disease (London: Longmans, Green \& Co., 1888), 1-2.

${ }^{12}$ Ibid., 4.

${ }^{13}$ Nancy Holroyde-Downing, 'Mapping the Tongue: Travel and Transformation', presentation from 'The Future of Medical History' conference, The Wellcome Trust Centre for the History of Medicine at UCL, London, July 2010.

${ }^{14}$ John Abernethy, Surgical Observations on the Constitutional Origin and Treatment of Local
}

Diseases; And on Aneurysms (London: Longman, Hurst, Rees \& Orme, 1809), 22.

${ }^{15}$ For one of many contemporary accounts of Abernethy's consulting style see Anon., 'John Abernethy' [Pen and Ink Sketches of Poets, Preachers and Politicians, 1846], St. Bartholomew's Hospital Journal, XLI, 5 (1934), 87-90.

${ }^{16}$ Abernethy, op. cit. (note 14).

${ }^{17}$ Editorial, 'The Tongue in Diagnosis', The Lancet, 244, 6316 (1944), 381.

${ }^{18}$ T.H. Howell, 'Constipation and Furred Tongue', The Lancet, 279, 7244 (1962), 1413-4. 


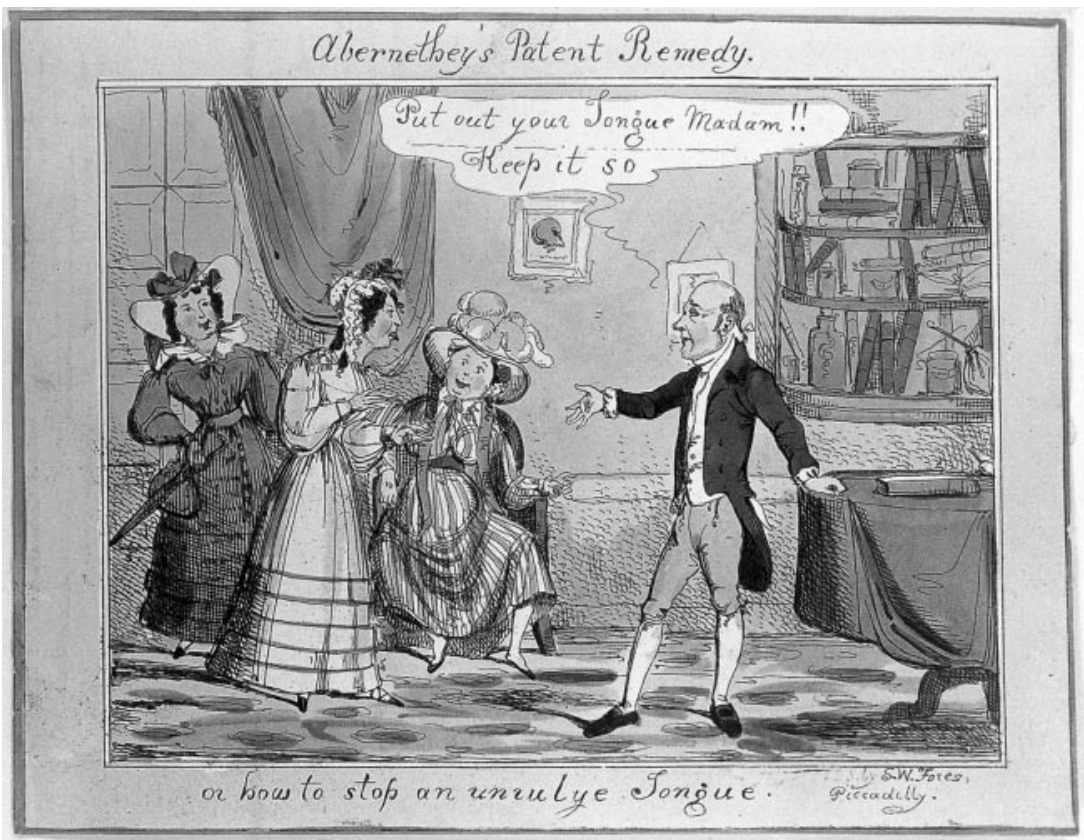

Figure 3 : 'Abernethy's patent remedy, or how to stop an unrulye tongue.' Coloured etching, S.W. Fores, 1825. Courtesy: Wellcome Library, London.

indication of general health besides some specific fevers, gastrointestinal, respiratory and nervous conditions, and anaemia. Indeed, practitioners appeared routinely to inspect the tongue without actually gaining, or using, much clinical information, even though their patients expected the practice and considered it valuable; Benjamin Ridge, an enthusiastic advocate of the tongue's diagnostic potential, took his colleagues to task for this:

On mentioning to intelligent non-professional men the probability that some parts of the tongue were more connected with certain organs than others, and that I believed in such connexions, and even pointed them out, I was always met by the observation that they did not consider this new, and they seemed to wonder at my simplicity in thinking it a discovery, for they remarked, that surely the Faculty generally has such a guide, as they always looked at the tongue; and why did they consult it but for this purpose? ${ }^{19}$

Lionel Beale even suggested that inspecting the tongue was a kind of ritual that the doctor performed almost unconsciously:

I dare say that many who tell patients to put out their tongues sometimes do it as a matter of routine. I have known a rather absent doctor tell the patient to put out his tongue several times in the course of a few minutes' medical conversation. Patients are sometimes a little prosy, and if there is not much the matter with them, you may not attend as diligently as you ought to. You lose the

\footnotetext{
${ }^{19}$ Benjamin Ridge, Glossology: Or the Additional

Indications and Appearances of the Tongue, $2^{\text {nd }}$ edn Means of Diagnosis of Disease to be derived from (London: Reynell \& Weight, 1857), 5-6 (his italics).
} 

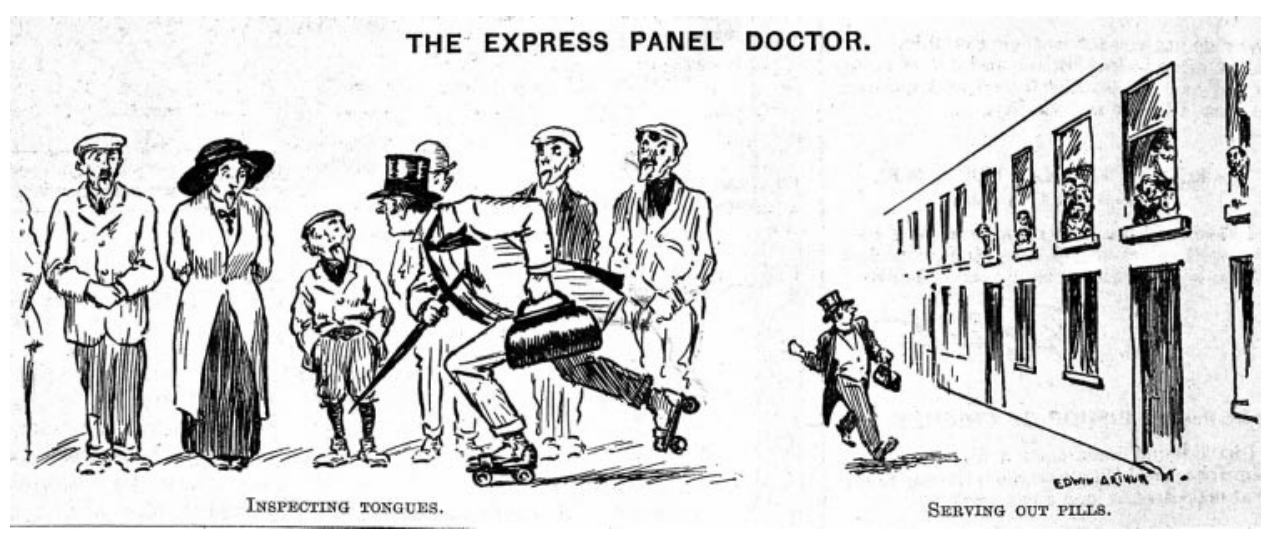

Figure 4: 'Express Panel Doctor', Punch (1913). Courtesy: Wellcome Library, London.

thread of the discourse, and while your wits are wandering you may cry out quite unconsciously, almost as if your command was the result of some reflex and habitual action, 'Put out your tongue', although the organ has been already more than once displayed for your examination. ${ }^{20}$

The prime function of tongue inspection might not, therefore, have been to glean clinical information. Where medical and lay accounts - written, iconographic, or anecdotal - do appear to converge, is in the widespread expectation that a nineteenth-century doctor who was doing his job, would look at the patient's tongue - and, generally, feel the pulse. Pathology was by now represented as localised disease of internal organs; perhaps observing the tongue offered reassurance that an internal organ had been directly inspected. But nineteenth-century rank-and-file practitioners were busy, working in an intensely competitive and crowded medical marketplace, often turning to newer opportunities for rapid-turnover medical practice - friendly societies, provident dispensaries, casualty departments towards the end of the nineteenth century and the panel system in the early twentieth. Conceiving disease as localised pathology implied that physical examination was often necessary to establish a diagnosis. An implicit social contract between doctor and patient ensured that tongue inspection - observation of an internal organ - and pulse palpation, with its physical touch and direct connection to the heart, would fit the bill. Once having performed these brief manoeuvres, the physician had established his authority to diagnose and treat his patient.

I began this account with a clinical observation, and shall tentatively conclude with another one. Assessing young children with acute respiratory infections forms part of my job as a clinician. Sometimes I am faced with a beaming, healthy infant who clearly has a cold. Before I can pronounce the child well, however, an implicit social convention dictates that I must solemnly examine the child's chest with my stethoscope; only then am I deemed to have the clinical and moral authority to diagnose and treat. Thus, I trace my clinical lineage to the overworked, tongue-inspecting physicians of Victorian Britain, who established their own clinical authority with the command, 'Put out your tongue!'

${ }^{20}$ Lionel S. Beale, On Slight Ailments: Their

Nature and Treatment (London: Churchill, 1882), 26. 